\title{
Development of a Model to Predict Liver Decompensation prior to Transarterial Chemoembolization Refractoriness in Patients with Intermediate-Stage Hepatocellular Carcinoma
}

\author{
Joel Ferreira-Silva ${ }^{a}$ Pedro Costa-Moreira ${ }^{a, b}$ Helder Cardoso ${ }^{a, b}$ \\ Rodrigo Liberal ${ }^{a, b}$ Pedro Pereira ${ }^{a, b}$ Guilherme Macedo ${ }^{a, b}$ \\ ${ }^{a}$ Gastroenterology Department, Hospital de São João, Porto, Portugal; ${ }^{b}$ Faculty of Medicine of the University of \\ Porto, Porto, Portugal
}

\section{Keywords}

Hepatocellular carcinoma $\cdot$ Transarterial

chemoembolization · Child-Pugh class

\begin{abstract}
Introduction: Transarterial chemoembolization (TACE) is the first-line treatment for patients with intermediate-stage hepatocellular carcinoma (HCC). For patients without an adequate response, current finding suggests that treatment with molecular target agents, approved for advanced stage, might present benefits. However, this requires a preserved liver function. This study aims to evaluate possible predictors of early deterioration of hepatic reserve, prior to TACE refractoriness, in a cohort of patients treated with TACE. Methods: Retrospective analysis of 99 patients with Child-Pugh class A and intermediate-stage HCC who underwent TACE as the first-line treatment. All patients were submitted to a biochemical and medical evaluation prior to initial TACE and every month afterward. Response to initial TACE was evaluated at 1 month. The time to Child-Pugh class deterioration before TACE refractoriness was assessed. Results: Ninety-
\end{abstract}

nine patients were included. Objective response rate (ORR) to initial TACE was assessed as present in 59 (63.4\%) and as absent in 34 (36.6\%) patients. Liver decompensated before TACE refractoriness in 51 (51.5\%) patients, and the median time to liver decompensation was 14 (IQR 8-20) months after first TACE. In multivariate analysis, beyond up-to-7 criteria (HR 2.4, $p=0.031$ ), albumin $<35 \mathrm{mg} / \mathrm{dL}$ (HR 3.5, $p<0.001$ ) and absence of ORR (HR 2.4, $p=0.020$ ) were associated with decreased overall survival free of liver decompensation. Moreover, beyond up-to-7 criteria, albumin $<35 \mathrm{mg} / \mathrm{dL}$ and absence of ORR associated negatively with 6-month survival free of liver decompensation. Our model created using those variables was able to predict liver decompensation at 6 months with an AUROC of $0.701(p=0.02)$. Conclusions: The absence of ORR after initial TACE, beyond up-to-7 criteria and albumin $<35 \mathrm{mg} / \mathrm{dL}$, was a predictive factor for early liver decompensation before TACE refractoriness in our population. Such patients might benefit from treatment escalation to systemic therapy, in monotherapy or in combination with TACE.
C 2021 Sociedade Portuguesa de Gastrenterologia Published by S. Karger AG, Basel karger@karger.com www.karger.com/pjg

Karger $\stackrel{\text { ' }}{5}$ BOPEN ACCESS (c) 2021 Sociedade Portuguesa de Gastrenterologia Published by S. Karger AG, Basel

This is an Open Access article licensed under the Creative Commons Attribution-NonCommercial-4.0 International License (CC BY-NC) (http://www.karger.com/Services/OpenAccessLicense), applicable to the online version of the article only. Usage and distribution for commercial purposes requires written permission.
Correspondence to:

Joel Ferreira-Silva,jom_73@ hotmail.com 
Desenvolvimento de um modelo preditor de descompensação hepática pré refratariedade a quimioembolização transarterial em doentes com carcinoma hepatocelular em estadio intermediário

\section{Palavras Chave}

Carcinoma hepatocellular · Quimioembolização transarterial $\cdot$ Classe Child-Pugh

\section{Resumo}

Introdução: A quimioembolização transarterial (TACE) é o tratamento de primeira linha para doentes com carcinoma hepatocelular (HCC) em estadio intermédio. Em doentes sem resposta adequada, a evidência atual sugere que o tratamento com agentes de alvo molecular, aprovado para estágio avançado, pode apresentar benefícios. Porém, isso requer função hepática preservada. O objetivo deste estudo é avaliar possíveis preditores de deterioração precoce da reserva hepática, antes da refratariedade ao TACE, em uma coorte de doentes tratados com TACE. Métodos: Análise retrospectiva de noventa e nove doentes com Child-Pugh classe A e HCC em estadio intermédio que foram submetidos a TACE como tratamento de primeira linha. Todos os doentes foram submetidos a uma avaliação bioquímica e médica antes do TACE inicial e a cada mês após. A resposta ao TACE inicial foi avaliada em 1 mês. $O$ tempo para a deterioração da classe Child-Pugh antes da refratariedade a TACE foi avaliado. Resultados: Noventa e nove doentes foram incluídos. A resposta radiológica objetiva (ORR) ao TACE inicial foi avaliada como presente em 59 (63.4\%) e ausente em 34 (36.6\%) doentes. Descompensação hepática ocorreu, antes da refratariedade a TACE, em 51 (51.5\%) doentes e o tempo médio para a descompensação hepática foi de 14 (IQR 8-20) meses, após o primeiro TACE. Na análise multivariada, além dos critérios up-to-7 (HR 2,4, $p=0.031$ ), albumina $<35 \mathrm{mg} / \mathrm{dL}$ (HR 3,5, $p<$ 0.001 ) e ausência de ORR (HR 2,4, $p=0.020$ ) foram associados a diminuição da sobrevida livre de descompensação hepática. Além disso, a sobrevida de 6 meses livre de descompensação hepática apresentou associação, além dos critérios up-to-7, albumina $<35 \mathrm{mg} / \mathrm{dL}$ e ausência de ORR. Foi criado um modelo com essas variáveis, capaz de prever a descompensação hepática com AUROC de 0,701 ( $p=0.02$ ). Conclusões: A ausência de ORR após TACE inicial, além dos critérios up-to-7 e albumina $<35$ $\mathrm{mg} / \mathrm{dL}$ foram fatores preditivos para descompensação hepática antes da refratariedade a TACE na nossa popu- lação. Esses doentes podem beneficiar do escalonamento do tratamento para a terapia sistêmica, em monoterapia ou em combinação com TACE.

(C) 2021 Sociedade Portuguesa de Gastrenterologia Publicado por S. Karger AG, Basel

\section{Introduction}

Transarterial chemoembolization (TACE) is the first-line treatment for patients with non-resectable hepatocellular carcinoma (HCC) in the absence of decompensated cirrhosis, large tumor size $(>10 \mathrm{~cm})$, comorbidities, portal vein thrombosis, or extrahepatic spread [1-3]. The survival benefit of TACE in patients with intermediate-stage HCC is well established [4]. However, this therapy frequently loses its therapeutic efficacy over time, despite repeated procedures, leading to TACE refractoriness [5].

For patients without an adequate response after TACE, the concept of therapeutic stage migration can be considered [6]. Systemic therapy (ST) has been demonstrated to be effective in patients after TACE failure [7]. Furthermore, recent studies suggest that, in patients with HCC and TACE refractoriness, ST might improve the prognosis, when compared with repeated TACE procedures [8-10]. Moreover, several studies demonstrate a benefit of systemic treatment as an adjuvant to TACE [11]. As such, ST can be considered in patients with intermediate-stage HCC $[1,7]$. However, ST, similar to locoregional therapy, requires preserved liver function, and patients that develop early deterioration of liver function following TACE are deprived of ST as a therapeutic option [12]. To complicate matters, up to $25 \%$ of patients with TACE refractoriness develop Child-Pugh $\mathrm{B} / \mathrm{C}$ after initial TACE $[8,9]$. Furthermore, it has previously been described that repeated TACE procedures are associated with deterioration of hepatic reserve, even though recent studies might challenge the relevance of this association $[11,13]$. Defining predictors of early liver decompensation in patients with HCC proposed to TACE could potentially help in better treatment selection in such patients. Previous works fail to propose predictors of early deterioration of liver function before TACE refractoriness.

This study aims to evaluate possible predictors of overall and 6-month survival free of liver decompensation before TACE refractoriness in a cohort of Western patients with intermediate-stage HCC submitted to TACE. 
Fig. 1. Flowchart regarding patient selection. HCC, hepatocellular carcinoma; TACE, transarterial chemoembolization.

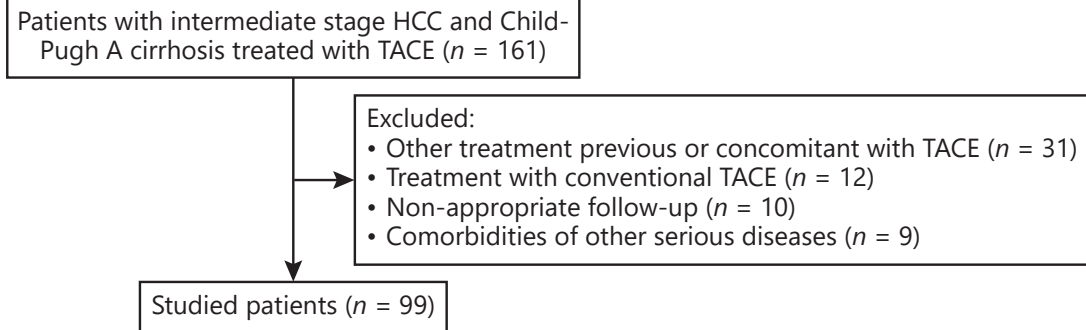

Studied patients $(n=99)$

\section{Material and Methods}

\section{Study Design}

We performed a retrospective study of all consecutive patients with intermediate-stage HCC submitted to drug-eluting polyvinyl alcohol microspheres TACE (DEM-TACE), as proposed by a multidisciplinary board, in a tertiary center between January 2010 and October 2020. This study was carried out in compliance with the ethical principles outlined in the Declaration of Helsinki and was approved by the Ethical Committee of our center. The requirement for written informed consent was waived. Inclusion criteria where: (i) radiological or histological evidence of HCC in accordance with the diagnosis criteria of American Association for the Study of Liver Diseases guidelines, (ii) intermediate-stage HCC in accordance with Barcelona Clinic Liver Cancer staging system, (iii) Child-Pugh class A cirrhosis before DEM-TACE, and (iii) treatment with TACE. Exclusion criteria were: (i) comorbidities of other serious diseases (American Society of Anesthesiologists physical status >2), (ii) lack of appropriate follow-up (clinical evaluation or radiological tumor evaluation within 3 months after initial DEM-TACE), (iii) other treatment previous or concomitant with TACE, and (iv) treatment with conventional TACE [14]. All patients were submitted to a biochemical and medical evaluation before initial TACE.

\section{Transarterial Chemoembolization Procedure and Subsequent}

Follow-Up

After catheter insertion in the celiac artery, guided by angiography, a microcatheter injects contrast into the common hepatic artery, identifying the arteries that feed the tumor. The microcatheter is then advanced as far as possible in the segmental or subsegmental branches feeding the tumor. Drug-eluting microspheres loaded with doxorubicin are injected into the tumor's supply arteries until blood flow is obstructed. The selection of doxorubicin dose is determined by our institution's protocol.

Objective response rate (ORR) to TACE was evaluated 1 month after each procedure with magnetic resonance or computer tomography scan, in accordance with modified response evaluation criteria in solid tumors (mRECIST) [15]. Subsequently, every 3 months imaging was performed and intrahepatic recurrences or presence of viable tumors dictated additional treatment, TACE, or other indicated treatment depending on TACE refractoriness criteria.

Adverse events were accessed retrospectively in patient records and were classified according to Common Terminology Criteria of Adverse Events (CTCAE) 5.0 [16]. Only CTCAE grade $\geq 3$ adverse events were recorded.

Liver Decompensation in IntermediateStage HCC
Definition of TACE Responder, Liver Decompensation, and TACE Refractoriness

ORR was defined as (i) present in patients with complete response or partial response and as (ii) absent in patients with stable disease or progressive disease in accordance with mRECIST criteria. Liver decompensation was defined as irreversible exacerbation from Child-Pugh class A to Child-Pugh class B or C after first TACE. TACE refractoriness, in accordance with the Japan Society of Hepatology, was defined as (i) $\geq 2$ TACE procedures with each reevaluation showing progression in tumor number or insufficient response of the treated tumors (viable lesions $>50 \%$ ) or (ii) appearance of extrahepatic spread or vascular invasion [17].

\section{Outcomes}

The primary outcome was overall survival free of liver decompensation, defined as the time interval from the first TACE to liver decompensation. Secondary outcomes were 6-month survival free of liver decompensation, overall survival free of TACE refractoriness (time interval from the first TACE to TACE refractoriness), and overall survival (time from the first TACE to death).

\section{Statistical Analysis}

All variables were presented as categorical variables, with counts and percentages. Overall survival free of liver decompensation was defined as the time interval between initial TACE and development of liver decompensation. Patients who survived without liver decompensation at the last follow-up date (December 10, 2020) or were lost to follow-up were censored. Patients with TACE refractoriness before liver decompensation were censored at the time of TACE refractoriness. Overall survival free of liver decompensation rates were estimated using the Kaplan-Meier method and compared using the log-rank test. Multivariable analysis, using Coxregression, was performed for the analysis of the following outcomes: overall and 6-month survival free of liver decompensation, overall survival free of TACE refractoriness, and overall survival. All variables statistically significant in the previous univariable analysis were included in this analysis. Multiple imputations had been performed with 5 independent draws for missing values. The interactions between predictors were also tested.

Possible models for risk stratification of overall survival free of liver decompensation were then developed based on the above analyses and performance was measured by likelihood ratio chisquare. A ROC curve analysis was developed to determine the best cut-off value for the model. Kaplan-Meier analysis compared overall survival free of liver decompensation between the two groups created. 
Table 1. Baseline characteristics

\begin{tabular}{|c|c|}
\hline Parameter & $n(\%)$ \\
\hline \multicolumn{2}{|l|}{ Sex } \\
\hline Female & $20(20.2 \%)$ \\
\hline Male & 79 (79.8\%) \\
\hline \multicolumn{2}{|l|}{ Age, years } \\
\hline$<60$ & $24(24.2 \%)$ \\
\hline $60-70$ & $21(21.2 \%)$ \\
\hline$>70$ & $54(54.5 \%)$ \\
\hline \multicolumn{2}{|l|}{ Etiology } \\
\hline Alcohol & 42 (42.4\%) \\
\hline $\mathrm{HCV}$ & 34 (34.3\%) \\
\hline HBV & $7(7.1 \%)$ \\
\hline $\mathrm{NASH}$ & $5(5.1 \%)$ \\
\hline Others & $11(11.1 \%)$ \\
\hline \multicolumn{2}{|c|}{ Tumor size, mm } \\
\hline$<50$ & $86(86.8 \%)$ \\
\hline $50-70$ & $7(7.1 \%)$ \\
\hline$>70$ & $6(6.1 \%)$ \\
\hline \multicolumn{2}{|c|}{ Number of nodules } \\
\hline 1 & $58(58.6 \%)$ \\
\hline 2 & $25(25.3 \%)$ \\
\hline 3 & $8(8.1 \%)$ \\
\hline$>3$ & $8(8.1 \%)$ \\
\hline \multicolumn{2}{|l|}{ Up-to-7 } \\
\hline Within & 81 (81.8\%) \\
\hline Beyond & $18(18.2 \%)$ \\
\hline \multicolumn{2}{|c|}{ Albumin, g/L } \\
\hline$\leq 35$ & 43 (43.4\%) \\
\hline$>35$ & $56(56.6 \%)$ \\
\hline \multicolumn{2}{|c|}{ Bilirubin, mg/dL } \\
\hline$<2$ & $78(78.8 \%)$ \\
\hline$\geq 2$ & 21 (21.2\%) \\
\hline \multicolumn{2}{|c|}{ Platelets, $\times 10^{9}$} \\
\hline$\geq 150$ & $43(43.4 \%)$ \\
\hline$<150$ & $56(56.6 \%)$ \\
\hline \multicolumn{2}{|l|}{$\mathrm{AFP}, \mathrm{ng} / \mathrm{mL}$} \\
\hline$<20$ & $61(61.6 \%)$ \\
\hline$\geq 20$ & $38(38.4 \%)$ \\
\hline \multicolumn{2}{|l|}{ ORR } \\
\hline Present & 41 (41.4\%) \\
\hline Absent & $58(58.6 \%)$ \\
\hline \multicolumn{2}{|c|}{ TACE procedures } \\
\hline 1 & $32(32.3 \%)$ \\
\hline 2 & 34 (34.3\%) \\
\hline 3 & $17(17.2 \%)$ \\
\hline$\geq 4$ & $16(16.2 \%)$ \\
\hline \multicolumn{2}{|c|}{ Doxorubicin, mg } \\
\hline$<35$ & $22(22.2 \%)$ \\
\hline $35-70$ & $28(28.3 \%)$ \\
\hline$\geq 70$ & 49 (49.5\%) \\
\hline
\end{tabular}

$\mathrm{HCV}$, hepatitis C virus; HBV, hepatitis B virus; NASH, non-alcoholic steatohepatitis; BCLC, Barcelona Clinic Liver Cancer; AFP, alphafetoprotein; ORR, objective radiological response at 1 month after first transarterial chemoembolization; TACE, transarterial chemoembolization.
Differences were considered statistically significant when corresponding $p$ values were less than 0.05 . All statistical analyses were performed using SPSS Version 23 (IBM Corporation, Chicago, IL, USA).

\section{Results}

\section{Patients' Baseline Characteristics}

From a total of 161 patients with intermediate-stage HCC and Child-Pugh A cirrhosis treated with TACE, 99 patients were included (Fig. 1). Mean age was 73 (IQR 59-86) years, 78 (79\%) were male. Median follow-up time was 40 (IQR 11-62) months. The etiology of hepatic disease was alcohol in $42 \%$, chronic hepatitis $\mathrm{C}$ in $34 \%$, chronic hepatitis B (HBV) in 7\%, non-alcoholic steatohepatitis in 5\%, and others in $11 \%$ (Table 1). Median tumor size was $37 \mathrm{~mm}(10-180 \mathrm{~mm})$. Median tumor number of nodules was 1.6 (IQR 1-2). Eighty-one patients (82\%) were within up-to-7 criteria and 18 patients (18\%) were beyond up-to-7 criteria. Median albumin was 35.5 $\mathrm{g} / \mathrm{L}$ (IQR 34-38), median bilirubin was $1 \mathrm{mg} / \mathrm{dL}$ (IQR $0.7-1.5$ ), median alpha-fetoprotein was $10.9 \mathrm{ng} / \mathrm{mL}$ (IQR 4-70), and median international normalized ratio was 1.2 (IQR 1.1-1.3). No patient presented ascites or hepatic encephalopathy.

\section{Overall and 6-Month Survival Free of Liver}

Decompensation before TACE Refractoriness

Liver function deteriorated to Child-Pugh B/C before TACE refractoriness in $51(51.5 \%)$ patients and median time to liver decompensation was 14 (IQR 8-20) months, after first TACE. In univariable analysis, overall survival free of liver decompensation was significantly longer in patients within versus beyond upto- 7 criteria (median, 40.9 vs. $20.3, p=0.041$ ), albumin $>35$ versus $\leq 35 \mathrm{mg} / \mathrm{dL}$ (median, 43.7 vs. 24.5 months, $p<0.001$ ), bilirubin $<2$ versus $\geq 2 \mathrm{mg} / \mathrm{dL}$ (median, 43.9 vs. 18.9 months, $p=0.029$ ), and presence versus absence of ORR (median, 56.7 vs. 27.6 months, $p=0.002$ ) (Table 2 ). In multivariable analysis, beyond up-to-7 criteria (HR 2.4, $p=0.031$ ), albumin $<35 \mathrm{mg} / \mathrm{dL}$ (HR 3.5, $\mathrm{p}<$ 0.001 ), and absence of ORR (HR 2.4, $p=0.020$ ) presented a negative association with overall survival free of liver decompensation (Table 3). Moreover, 6-month survival free of liver decompensation presented a negative association, in multivariable analysis, with beyond up-to-7 criteria (HR 3.7, $p=0.012$ ), albumin $<35 \mathrm{mg} / \mathrm{dL}$ (HR 4.4, $p=0.006)$, and absence of ORR (HR 2.6, $p=$ 0.025) (Table 2). 
Table 2. Univariable analysis for overall survival free of liver decompensation, 6-month survival free of liver decompensation, survival free of TACE refractoriness, and overall survival

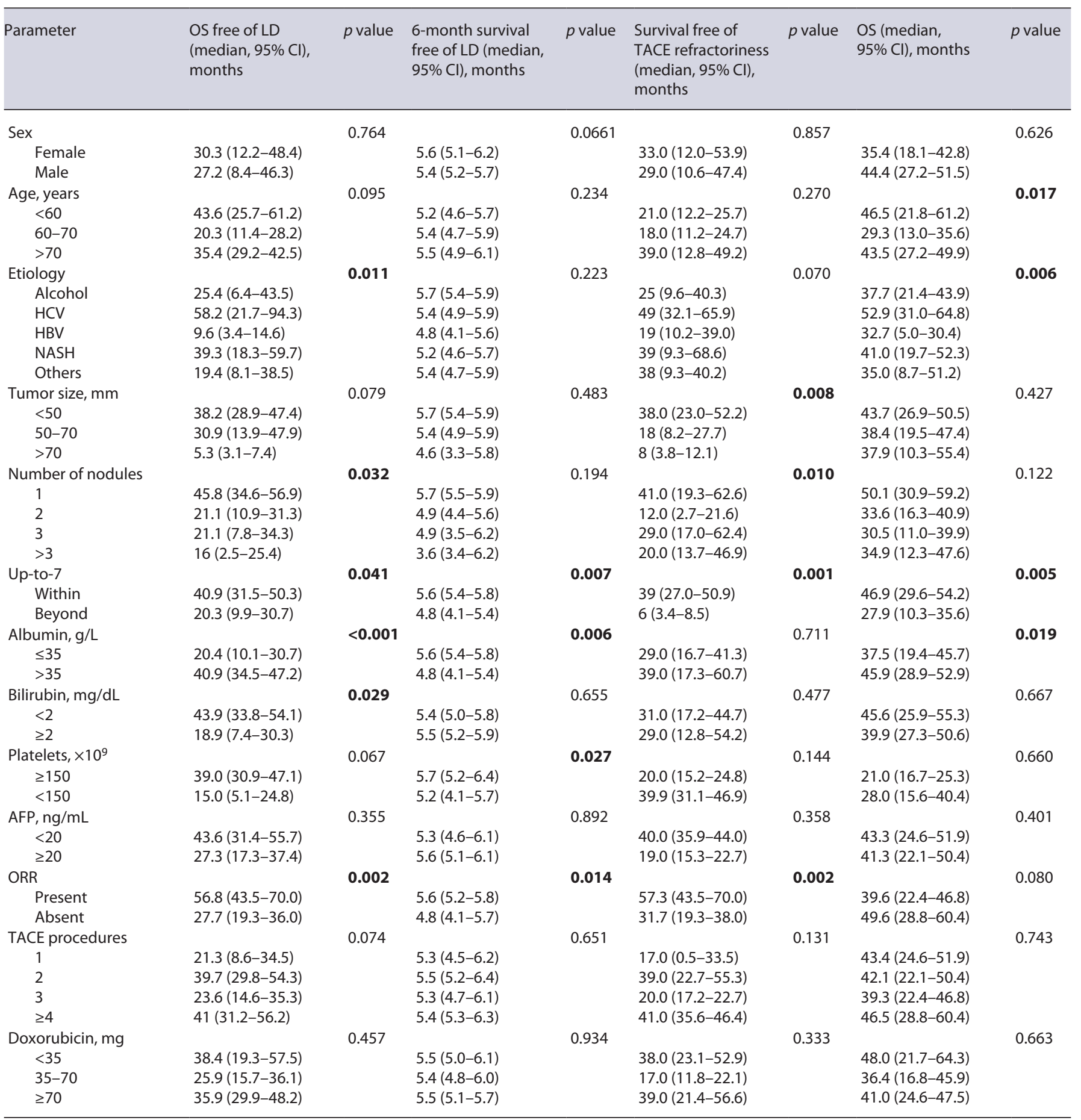

OS, overall survival; LD, liver decompensation; $\mathrm{Cl}$, confidence interval; $\mathrm{HCV}$, hepatitis C virus; $\mathrm{HBV}$, hepatitis B virus; $\mathrm{NASH}$, non-alcoholic steatohepatitis; BCLC, Barcelona Clinic Liver Cancer; AFP, alpha-fetoprotein; ORR, objective radiological response at 1 month after first transarterial chemoembolization; TACE, transarterial chemoembolization.

Liver Decompensation in IntermediateStage HCC
GE Port J Gastroenterol 2023;30:29-37 DOI: $10.1159 / 000520530$ 
Table 3. Multivariable analysis for overall survival free of liver decompensation, 6-month survival free of liver function deterioration, survival free of TACE refractoriness, and overall survival

\begin{tabular}{|c|c|c|c|c|c|c|c|c|}
\hline \multirow[t]{2}{*}{ Parameter } & \multicolumn{2}{|l|}{ OS free of LD } & \multicolumn{2}{|c|}{$\begin{array}{l}\text { 6-month survival free } \\
\text { of } L D\end{array}$} & \multicolumn{2}{|c|}{$\begin{array}{l}\text { Survival free of TACE } \\
\text { refractoriness }\end{array}$} & \multicolumn{2}{|l|}{ OS } \\
\hline & $\begin{array}{l}\text { hazard ratio } \\
(95 \% \mathrm{Cl})\end{array}$ & $p$ value & $\begin{array}{l}\text { hazard ratio } \\
(95 \% \mathrm{Cl})\end{array}$ & $p$ value & $\begin{array}{l}\text { hazard ratio } \\
(95 \% \mathrm{Cl})\end{array}$ & $p$ value & $\begin{array}{l}\text { hazard ratio } \\
(95 \% \mathrm{Cl})\end{array}$ & $p$ value \\
\hline \multicolumn{9}{|l|}{ Age, years } \\
\hline$\leq 70$ & 1 & - & 1 & - & 1 & - & 1 & - \\
\hline$>70$ & $2.6(0.7-8.6)$ & 0.246 & $1.7(0.6-7.1)$ & 0.275 & $1.9(0.5-6.5)$ & 0.623 & $2.4(1.3-8.1)$ & 0.012 \\
\hline HBV & $4.0(0.8-11.1)$ & 0.123 & $1.7(0.4-8.1)$ & 0.483 & $1.2(0.2-9.5)$ & 0.844 & $1.4(0.8-5.1)$ & 0.237 \\
\hline \multicolumn{9}{|l|}{ Up-to-7 } \\
\hline Within & 1 & - & 1 & - & 1 & - & 1 & - \\
\hline Beyond & $2.4(1.1-5.5)$ & 0.031 & $3.7(1.3-10.1)$ & 0.012 & $3.9(1.8-8.3)$ & 0.001 & $2.4(1.2-4.7)$ & 0.011 \\
\hline \multicolumn{9}{|l|}{ Albumin, $\mathrm{g} / \mathrm{L}$} \\
\hline$>35$ & 1 & - & 1 & - & 1 & - & 1 & - \\
\hline$\geq 150$ & 1 & - & 1 & - & 1 & - & 1 & - \\
\hline$<150$ & $2.4(1.1-5.5)$ & 0.343 & $3.1(0.8-9.1)$ & 0.127 & $1.7(0.6-7.1)$ & 0.275 & $1.8(0.7-2.8)$ & 0.387 \\
\hline \multicolumn{9}{|l|}{ ORR } \\
\hline Present & 1 & - & 1 & - & 1 & - & 1 & - \\
\hline Absent & $2.4(1.1-5.2)$ & 0.020 & $2.8(1.2-8.1)$ & 0.025 & $2.7(1.1-3.5)$ & 0.025 & $1.6(0.8-2.5)$ & 0.074 \\
\hline
\end{tabular}

OS, overall survival; LD, liver decompensation; $\mathrm{Cl}$, confidence interval; $\mathrm{HBV}$, hepatitis B virus; ORR, objective radiological response at 1 month after first transarterial chemoembolization.

Table 4. Six-month survival free of liver decompensation for patients stratified as low- or high-risk in accordance with out model

\begin{tabular}{lll}
\hline Model classification & $\begin{array}{l}\text { 6-month SFLD } \\
\text { (median, 95\% Cl), months }\end{array}$ & $p$ value \\
\hline Low-risk & 26.1 & 0.002 \\
High-risk & 50.9 & \\
\hline
\end{tabular}

SFLD, survival free of liver decompensation.

Using up-to-7-criteria, albumin, and ORR, we created a model predictive of 6-month survival free liver decompensation. The model formula is: 1.601 (if beyond upto-7 criteria) -0.428 (if albumin $>35 \mathrm{mg} / \mathrm{dL}$ ) -0.464 (if presence of ORR) - 1.285.

ROC curve presented an AUROC $0.701(p=0.006)$ for the prediction of liver decompensation at 6 months. Using the cut-off value of -1.49 , the model presented a sensitivity of $81 \%$ and a specificity of $72 \%$ for liver decompensation at 6 months.
We used the cut-off value of -1.49 to classify patients as low-risk $(<-1.49)$ and high-risk $(\geq-1.49)$ in accordance with the model developed. Patients classified as high-risk $(n=52)$ presented a higher prevalence of liver decompensation (35\%) when compared with patients classified as low-risk (10\%). This difference was statistically significant in chi-square test $(p=0.022)$. Furthermore, in Kaplan-Meyer analysis, high-risk patients presented smaller overall survival free of liver decompensation when compared to low-risk patients (median, 26.1 vs. 50.9 months, $p=0.002$ ) (Fig. 2; Table 4).

\section{Transarterial Chemoembolization Treatment}

Outcome

The median TACE procedures per patient was 2 (IQR $1-3)$ and 41 patients (41\%) presented ORR after first TACE. Fifty (51\%) patients developed TACE refractoriness during follow-up and the median time to TACE refractoriness was 33 (IQR 11.7-54.3) months. Twelve (12.1\%) patients presented post chemoembolization syndrome. No other major (CTCAE grade $\geq 3$ ) complications related to TACE were registered. 


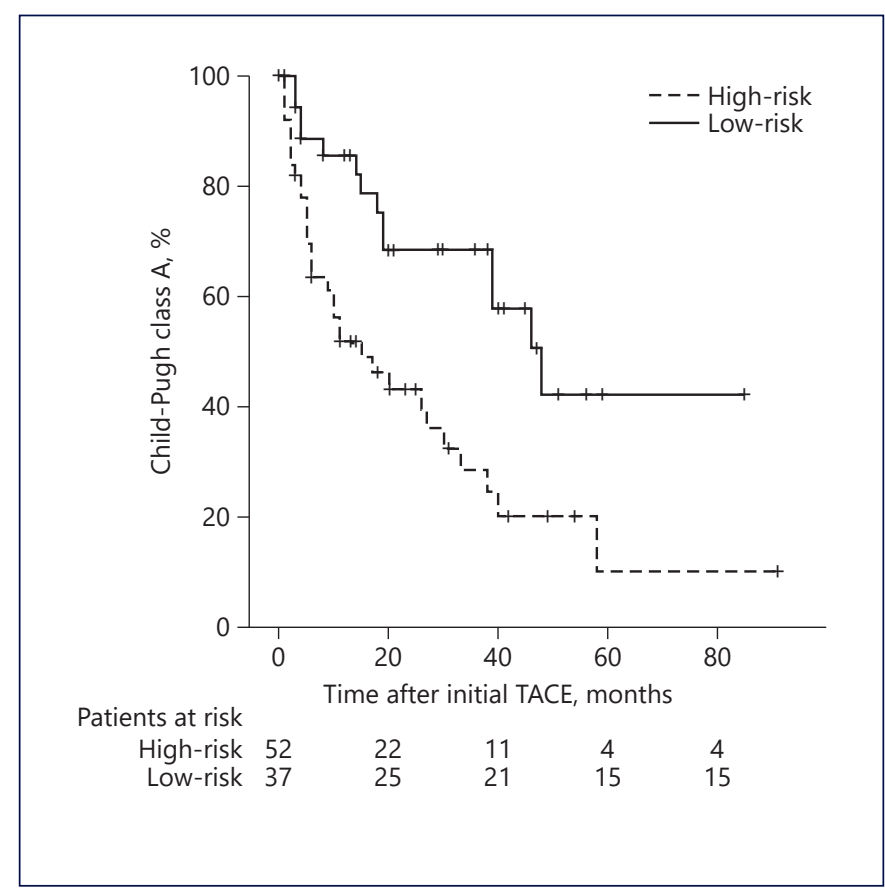

Fig. 2. Kaplan-Meier curves for the time to Child-Pugh class deterioration in patients with intermediate-stage hepatocellular carcinoma who underwent transarterial chemoembolization (TACE) as first-line treatment. Comparing patients classified as high-risk and low-risk in accordance with our model using the cut-off value of -1.49 .

In univariable analysis, up-to-7 criteria, number of nodules, total tumor size, and absence of ORR were identified as predictive factors associated with survival free of TACE refractoriness (Table 2). In multivariable analysis, beyond up-to-7 criteria and absence of ORR were identified as predictive factors of survival free of TACE refractoriness (Table 3).

\section{Overall Survival}

Presence of liver decompensation at 6 months after initial TACE was negatively associated with overall survival. Median survival was 38.7 (IQR 31.2-46.1) months for patients with Child-Pugh A and 12 (IQR 8.6-15.3) months for patients with Child-Pugh $\mathrm{B} / \mathrm{C}$ at 6 -month evaluation post first TACE procedure. This difference was statistically significant $(p<0.001)$. Moreover, albu$\min <35$ and beyond up-to-7 criteria were also negatively associated with overall survival in univariable analysis (Table 2). In multivariable analysis, beyond up-to-7 criteria (HR 2.4, $p=0.011$ ) and albumin $<35 \mathrm{mg} / \mathrm{dL}$ (HR 1.7, $p<0.042)$ were negatively associated with overall survival (Table 3).

Liver Decompensation in IntermediateStage HCC

\section{Discussion}

Based on our findings, we suggest that baseline albu$\min <35 \mathrm{~g} / \mathrm{L}$, beyond up-to-7 criteria, and absence of response to initial TACE are predictors of liver decompensation to Child-Pugh B/C before TACE refractoriness, in patients with intermediate-stage HCC submitted to TACE. Moreover, early ( 6 months) liver decompensation was associated with baseline albumin $<35 \mathrm{~g} / \mathrm{L}$, beyond up-to-7 criteria, and absence of response to initial TACE. Indeed, our model created using those variables was able to predict liver decompensation after initial TACE, and patients classified as high risk presented shorter survival free of liver decompensation.

Previous studies associated different markers of liver function and tumor burden as predictors of liver decompensation. However, those studies did not attempt to focus on predictors of liver decompensation before TACE refractoriness [18-20]. Furthermore, previous studies fail to analyze a specific population of patients with intermediate-stage HCC or a population exclusively treated with DEM-TACE. Identification of predictors of liver decompensation previous to TACE refractoriness is specifically useful in patients with intermediate-stage HCC, since the concept of therapeutic stage migration could be anticipated in such patients before TACE refractoriness. Furthermore, DEM-TACE, as opposed to conventional TACE or transarterial embolization is currently the most commonly used locoregional procedure in intermediatestage HCC, with a better security profile and, in some studies, better efficacy [21-23]. Facciorusso et al. report a meta-analysis that evaluated the efficacy and safety of TACE versus bland embolization [23]. In this study no differences in survival were identified. However, despite the apparently worst security profile of conventional TACE versus bland embolization, DEM-TACE in particular appears to present lower rates of adverse events. Indeed, in our population, only twelve patients presented postembolization syndrome and no other complications were registered. Also, being a single-center study, TACE procedures were standardized and the choice of anticancer agents was uniformized.

The ORR is proposed as a prognostic tool and is useful in the selection of retreatment strategies [1]. Assessment for retreatment with TACE (ART) score is a scoring system using radiological response to initial TACE as a tool useful in the selection of patients that do not benefit from additional TACE $[24,25]$. Our findings suggest ORR might also be useful to predict early liver dysfunction before TACE refractoriness.

GE Port J Gastroenterol 2023;30:29-37

DOI: $10.1159 / 000520530$ 
Cumulative TACE procedure has been previously identified as a risk factor for liver decompensation [13, 26]. However, the number of TACE procedures and cumulative doxorubicin dose did not present an association with overall survival free of liver decompensation in our population. This could be explained by the type of locoregional therapy used. In our population, only DEM-TACE was used, contrary to previous studies. DEM-TACE presents less toxicity to liver function as opposed to conventional TACE $[21,22]$.

The concept of TACE refractoriness is useful to consider the opportunity to switch from TACE retreatment to ST $[8,17]$. Previous studies demonstrated an association between liver decompensation and TACE refractoriness [18]. Indeed, in our population, beyond up-to-7 criteria and absence of ORR were independently associated with both liver decompensation and TACE refractoriness. As such, patients beyond up-to-7 criteria, with absence of ORR, or with albumin $<35 \mathrm{~g} / \mathrm{L}$ not only have a smaller window of opportunity to initiate ST but have a greater probability of TACE refractoriness.

Several randomized controlled trials evaluating efficacy and safety of ST plus TACE or TACE alone in patients with intermediate-stage HCC have been done and others are currently in progress $[11,27]$. Such studies have, so far, suggested a benefit in progression-free survival with this combination. However, the sub-population of patients who benefit the most from this combination is not yet described. We hypothesize that patients classified as high-risk of liver decompensation, using our model, might benefit from inclusion in such studies.

Furthermore, overall survival in patients with HCC treated with locoregional therapy is influenced by both recurrence and successive treatments. Previous studies demonstrate that a significant portion of patients experience HCC recurrence after locoregional therapy [28]. In patients with recurrence with advance-stage HCC, ST is the only palliate treatment available. Such patients are deprived of this option in the presence of liver decompensation. Patients classified as high-risk of liver decompensation, using our model, present an increased risk of liver decompensation and in consequence, might have an increased risk of being deprived of adequate treatment in case of HCC recurrence.

As a retrospective study, there are some limitations from the presence of possible bias. Moreover, sample size limited the number of variables included in multivariable analysis, and only significant variables in univariable analysis were included. Further prospective large studies are necessary to confirm our results.
In conclusion, our findings suggest that in patients with intermediate-stage HCC and Child-Pugh class A, beyond up-to- 7 criteria, albumin $<35 \mathrm{mg} / \mathrm{dL}$, and absence of ORR to initial TACE are predictors of early liver decompensation before TACE refractoriness. We created a model using those variables that is able to predict liver decompensation. Patients classified as high risk using this model have a smaller window of opportunity for alternative therapies and might benefit from inclusion in TACE plus ST combination therapy or ST monotherapy clinical trials.

\section{Statement of Ethics}

This study was carried out in compliance with the ethical principles outlined in the Declaration of Helsinki and was approved by the Ethical Committee of our center. The requirement for written informed consent was waived.

\section{Conflict of Interest Statement}

The authors have no conflicts of interest to declare.

\section{Funding Sources}

The authors have no funding to declare.

\section{Author Contributions}

J.F.-S. conceived the study. J.F.-S. and H.C. designed the study. J.F.-S. and P.C.-M. performed data collection. J.F.-S., H.C., R.L., and P.P. undertook the bibliographic research and drafted the manuscript. G.M. critically revised the draft and approved the final paper.

\section{References}

1 Galle PR, Tovoli F, Foerster F, Wörns MA, Cucchetti A, Bolondi L. The treatment of intermediate stage tumours beyond TACE: from surgery to systemic therapy. J Hepatol. 2017 Jul;67(1):173-83.

2 Raoul JL, Sangro B, Forner A, Mazzaferro V, Piscaglia F, Bolondi L, et al. Evolving strategies for the management of intermediatestage hepatocellular carcinoma: available evidence and expert opinion on the use of transarterial chemoembolization. Cancer Treat Rev. 2011 May;37(3):212-20.

3 de Lope CR, Tremosini S, Forner A, Reig M, Bruix J. Management of HCC. J Hepatol. 2012;56 Suppl 1:S75-87.
Ferreira-Silva et al. 
4 Marrero JA, Kulik LM, Sirlin CB, Zhu AX, Finn RS, Abecassis MM, et al. Diagnosis, staging, and management of hepatocellular carcinoma: 2018 practice guidance by the American Association for the Study of Liver Diseases. Hepatology. 2018 Aug;68(2):723-50.

5 Burrel M, Reig M, Forner A, Barrufet M, de Lope CR, Tremosini S, et al. Survival of patients with hepatocellular carcinoma treated by transarterial chemoembolisation (TACE) using Drug Eluting Beads. Implications for clinical practice and trial design. J Hepatol. 2012 Jun;56(6):1330-5.

6 Vitale A, Trevisani F, Farinati F, Cillo U. Treatment of Hepatocellular Carcinoma in the Precision Medicine Era: From Treatment Stage Migration to Therapeutic Hierarchy. Hepatology. 2020 Dec;72(6):2206-18.

7 Bruix J, Raoul JL, Sherman M, Mazzaferro V, Bolondi L, Craxi A, et al. Efficacy and safety of sorafenib in patients with advanced hepatocellular carcinoma: subanalyses of a phase III trial. J Hepatol. 2012 Oct;57(4):821-9.

8 Ogasawara S, Chiba T, Ooka Y, Kanogawa N, Motoyama T, Suzuki E, et al. Efficacy of sorafenib in intermediate-stage hepatocellular carcinoma patients refractory to transarterial chemoembolization. Oncology. 2014; 87(6):330-41.

9 Arizumi T, Ueshima K, Minami T, Kono M, Chishina $\mathrm{H}$, Takita $\mathrm{M}$, et al. Effectiveness of sorafenib in patients with transcatheter arterial chemoembolization (TACE) refractory and intermediate-stage hepatocellular carcinoma. Liver Cancer. 2015 Dec;4(4):253-62.

10 Peck-Radosavljevic M, et al. Outcomes of patients (pts) with hepatocellular carcinoma (HCC) treated with transarterial chemoembolization (TACE): Global OPTIMIS final analysis. American Society of Clinical Oncology; 2018.

11 Kudo M, Ueshima K, Ikeda M, Torimura T, Tanabe N, Aikata H, et al.; TACTICS study group. Randomised, multicentre prospective trial of transarterial chemoembolisation (TACE) plus sorafenib as compared with TACE alone in patients with hepatocellular carcinoma: TACTICS trial. Gut. 2020 Aug; 69(8):1492-501.
12 Abou-Alfa GK, Amadori D, Santoro A, Figer A, De Greve J, Lathia C, et al. Safety and efficacy of sorafenib in patients with hepatocellular carcinoma (HCC) and Child-Pugh A versus B cirrhosis. Gastrointest Cancer Res. 2011 Mar;4(2):40-4.

13 Hiraoka A, Kumada T, Kudo M, Hirooka M, Koizumi Y, Hiasa Y, et al.; Real-life Practice Experts for HCC (RELPEC) Study Group and HCC 48 Group (hepatocellular carcinoma experts from 48 clinics). Hepatic function during repeated TACE procedures and prognosis after introducing sorafenib in patients with unresectable hepatocellular carcinoma: multicenter analysis. Dig Dis. 2017;35(6):602-10.

14 Mayhew D, Mendonca V, Murthy BV. A review of ASA physical status - historical perspectives and modern developments. Anaesthesia. 2019 Mar;74(3):373-9.

15 Lencioni R, Llovet JM. Modified RECIST (mRECIST) assessment for hepatocellular carcinoma. in Seminars in liver disease. 2010. ${ }^{\circ}$ Thieme Medical Publishers.

16 Trotti A, Colevas AD, Setser A, Rusch V, Jaques D, Budach V, et al. CTCAE v3.0: development of a comprehensive grading system for the adverse effects of cancer treatment. Semin Radiat Oncol. 2003 Jul;13(3):176-81.

17 Kudo M, Matsui O, Izumi N, Iijima H, Kadoya M, Imai Y, et al.; Liver Cancer Study Group of Japan. JSH Consensus-Based Clinical Practice Guidelines for the Management of Hepatocellular Carcinoma: 2014 Update by the Liver Cancer Study Group of Japan. Liver Cancer. 2014 Oct;3(3-4):458-68.

18 Kohla MA, Abu Zeid MI, Al-Warraky M, Taha H, Gish RG. Predictors of hepatic decompensation after TACE for hepatocellular carcinoma. BMJ Open Gastroenterol. 2015 Jun;2(1):e000032.

19 Yasui Y, Tsuchiya K, Kurosaki M, Takeguchi T, Takeguchi Y, Okada M, et al. Up-to-seven criteria as a useful predictor for tumor downstaging to within Milan criteria and ChildPugh grade deterioration after initial conventional transarterial chemoembolization. Hepatol Res. 2018 May;48(6):442-50.
20 Eso Y, Takai A, Takahashi K, Ueda Y, Taura $\mathrm{K}$, Marusawa $\mathrm{H}$, et al. Combination of Mac-2 binding protein glycosylation isomer and upto-seven criteria as a useful predictor for Child-Pugh grade deterioration after transarterial chemoembolization for hepatocellular carcinoma. Cancers (Basel). 2019 Mar;11(3): 405

21 Ferrer Puchol MD, la Parra C, Esteban E, Vaño M, Forment M, Vera A, et al. Quimioembolización del hepatocarcinoma: partículas cargadas frente a quimioembolización convencional. Radiologia (Madr). 2011;53(3): 246-53.

22 Kloeckner R, Weinmann A, Prinz F, Pinto dos Santos D, Ruckes C, Dueber C, et al. Conventional transarterial chemoembolization versus drug-eluting bead transarterial chemoembolization for the treatment of hepatocellular carcinoma. BMC Cancer. 2015 Jun;15(1):465.

23 Facciorusso A, Bellanti F, Villani R, Salvatore V, Muscatiello N, Piscaglia F, et al. Transarterial chemoembolization vs bland embolization in hepatocellular carcinoma: A metaanalysis of randomized trials. United European Gastroenterol J. 2017 Jun;5(4):511-8.

24 Yin W, Ye Q, Wang F, Liang J, Xu B, Zhang $\mathrm{X}$, et al. ART score and hepatocellular carcinoma: an appraisal of its applicability. Clin Res Hepatol Gastroenterol. 2016 Dec;40(6): 705-14.

25 Tseng CL, Lai WJ, Huang CJ, Huang YH, Su CW, Lee IC, et al. The Effectiveness of ART Score in Selecting Patients for Transarterial Chemoembolization Retreatment: A Cohort Study in Taiwan. Medicine (Baltimore). 2015 Nov;94(47):e1659-1659.

26 Miksad RA, Ogasawara S, Xia F, Fellous M, Piscaglia F. Liver function changes after transarterial chemoembolization in US hepatocellular carcinoma patients: the LiverT study. BMC Cancer. 2019 Aug;19(1):795.

27 Hindson J. Combined TACE and sorafenib for HCC treatment. Nat Rev Gastroenterol Hepatol. 2020 Feb;17(2):66-66.

28 Facciorusso A, Del Prete V, Antonino M, Crucinio N, Neve V, Di Leo A, et al. Post-recurrence survival in hepatocellular carcinoma after percutaneous radiofrequency ablation. Dig Liver Dis. 2014 Nov;46(11):1014-9. 